\title{
ANALISIS RETORIKA KHOTBAH JUMAT DI MASJID NUR-ILAHI KELURAHAN GUNUNG ALAM KECAMATAN ARGA MAKMUR KABUPATEN BENGKULU UTARA
}

\author{
Fifi Alfionita Anggraini', Ngudining Rahayu², Bambang Djunaidi \\ Universitas Bengkulu ${ }^{1,2,3}$
}

Korespondesi.fifi.alfionita@yahoo.com

\begin{abstract}
Abstrak
Tujuan penelitian ini adalah untuk mendeskripsikan teknik persuasi dan ciri penanda lingual dalam retorika khotbah Jumat di Masjid Nur-Ilahi Kelurahan Gunung Alam Kecamatan Arga Makmur Kabupaten Bengkulu Utara. Metode yang digunakan dalam penelitian ini adalah metode deskriptif. Data penelitian ini berasal dari tuturan khatib yang mengandung teknik persuasi dan ciri penanda lingual yang terdapat dalam teknik persuasi tersebut. Teknik pengumpulan data penelitian ini adalah teknik observasi dan teknik rekaman. Teknik analisis data yang dilakukan adalah menggunakan analisis data kualitatif. Berdasarkan hasil penelitian dan pembahasan diperoleh bahwa pada bagian pendahuluan, isi, dan penutup khotbah ditemukan 5 teknik persuasi yaitu teknik persuasi secara langsung; teknik persuasi secara tidak langsung; teknik persuasi dengan menggunakan acuan/referensi; teknik persuasi dengan menggunakan analogi; dan teknik persuasi menggunakan harapan dan doa. Ciri penanda lingual dalam teknik persuasi tersebut adalah: (1) teknik persuasi secara langsung ditemukan enam variasi yang menjadi ciri penanda lingualnya yaitu menggunakan kata saya berpesan, marilah, kembali khatib mengingatkan, mari, kembali saya mengajak, dan selamatkan diri kita demi Allah selamatkan diri kita lari dari fitnah; (2) teknik persuasi secara tidak langsung ditemukan ciri penanda lingualnya yaitu maksud/ makna dari kutipan khatib (dilihat berdasarkan maksud yang disampaikan dalam tuturan khatib); (3) teknik persuasi dengan menggunakan acuan/referensi ditemukan ciri penanda lingualnya yaitu sebagaimana dalam Al-Quran, cerita hadits Nabi Mubammad, Allab berfirman, menurut Abdullah bin Mubarok (ulama), Nabi Mubammad bersabda, Abu Drar berkata, Rasulullab bersabda, kata para ulama, dialog Nabi dengan para sababat, dan dijelaskan dalam badits; (4) teknik persuasi dengan menggunakan analogi ditemukan ciri penanda lingualnya yaitu analogi balans atau neraca yang dianalogikakan dengan amal perbuatan manusia; (5) teknik persuasi menggunakan harapan dan doa ditemukan ciri penanda lingualnya yaitu mudah-mudahan dan semoga.
\end{abstract}

Kata Kunci: Analisis, Retorika, Khotbah Jumat, Teknik Persuasi, Penanda Lingual.

\section{ABSTRACT}

The purpose of this study was to describe persuasion techniques and lingual markers in the rhetoric of the Friday sermon at the Nur-Ilahi Mosque, Gunung Alam Village, Arga Makmur District, Bengkulu Utara Regency. The method used in this research was a descriptive method. The data of this study came from the preacher's utterances which contained persuasion techniques and lingual markers contained in the persuasion technique. The research data collection technique was the observation technique and the recording technique. The data analysis technique used was qualitative data analysis. Based on the results of research and discussion, 
it was found that in the introduction, content, and closing of the sermon, there are 5 persuasion techniques, namely direct persuasion techniques; indirect persuasion techniques; persuasion techniques using references; persuasion techniques using an analogy; and persuasion techniques using hope and prayer. Lingual markers in the persuasion technique are: (1) direct persuasion technique found six variations that characterize its lingual markers, namely using the word I give a message, come on, again the preacher reminded, come, again I invite, and save ourselves for the sake of Allah save ourselves from slander; (2) the persuasion technique indirectly found lingual markers, namely the meaning of the preacher's quote (seen based on the intent conveyed in the khatib's speech); (3) the persuasion technique by using a eferences found lingual markers, namely as in the Al-Quran, the story of the hadith of the Prophet Muhammad, Allah said, according to Abdullah bin Mubarok (ulama), Prophet Muhammad said, Abu Dhar said, Rasulullah said, said the scholars, the dialogue of the Prophet with his companions, and explained in the hadith; (4) the persuasion technique by using an analogy found lingual marker characteristics, namely the analogy of balances or a balance analogous to human deeds; (5) the persuasion technique using hope and prayer, the lingual markers are found, namely might and hopefully.

Keywords: Analysis, Rhetoric, Friday Sermon, Persuasion Techniques, Lingual Markers.

\section{PENDAHULUAN}

Retorika berarti kesenian untuk berbicara baik, yang dicapai berdasarkan bakat alam (talenta) dan keterampilan teknis (ars, techne). Retorika diartikan sebagai kesenian untuk berbicara baik, yang dipergunakan dalam proses komunikasi antar manusia. Kesenian berbicara ini bukan hanya berarti berbicara lancar tanpa jalan pikiran yang jelas dan tanpa isi, melainkan suatu kemampuan untuk berbicara dan berpidato secara singkat, jelas, padat dan mengesankan. Keterampilan dan kesanggupan untuk menguasasi seni berbicara ini dapat dicapai dengan mencontoh para retor yang terkenal (imitatio), dengan mempelajari dan mempergunakan hukum-hukum retorika (doctrina), dan dengan melakukan latihan yang teratur (exercitium) (Hendrikus, 1991: 14). Pendapat lain tentang retorika seperti yang dimuat oleh Anwar (2003: 3) retorika adalah alat utama untuk memperlancar dan mencapai tujuan dalam komunikasi.

Menurut Aristoteles dalam Oka (1976: 29) menampilkan retorika yakni sebuah ilmu yang berdiri sendiri, tujuannya adalah mempersuasi, yang di maksud persuasi dalam hubungan ini adalah meyakinkan pihak lain (penanggap tutur) akan kebenaran kasus yang dituturkan. Secara umum retorika tujuan sebagai berikut: (1) To convine, yakni meyakinkan atau menginsafkan pendengar, (2) To inform, yakni memberikan penerangan atau pemberitahuan kepada massa, (3) To inspire, yakni untuk menimbulkan inspirasi. (4) To entertain, yakni menimbulkan kegembiraan, menghibur atau menyenangkan.

Pembagian retorika terdiri dari monologika, dialogika, dan pembinaan teknik bicara. Monologika berarti ilmu tentang seni berbicara secara monolog, yakni hanya satu orang saja yang berbicara. Bentuk-bentuk yang tergolong dalam monologika yaitu pidato, ceramah, khotbah, kata sambutan, kuliah, makalah dan deklamasi. Sedangkan dialogika adalah ilmu tentang seni berbicara secara dialog, yaitu dua orang atau lebih berbicara atau mengambil bagian dalam satu proses pembicaraan (Hendrikus, 1991: 16). Bentuk dari dialogika seperti diskusi, tanya jawab, percakapan, dan debat. 


\section{Analisis Retorika Khotbah Jumat di Masjid Nur-llahi Kelurahan Gunung Alam}

Berbagai bentuk komunikasi di atas memiliki seni/retorika yang berbeda-beda disesuaikan dengan konteks yang ada dan kegiatan yang dilakukan, baik di konteks lingkungan pendidikan, luar pendidikan, dan juga saat proses menyampaikan sesuatu di depan pendengar. Khotbah Jumat merupakan salah satu bentuk dari retorika monologika yang memiliki seni tersendiri untuk mempersuasi jamaahnya dengan teknik retorika yang berbeda-beda setiap khatib berbicara antara satu dengan yang lain.

Retorika khotbah adalah cara pembicara dalam berbicara di depan muslim (khususnya laki-laki) di masjid pada saat proses salat Jumat dilakukan yang tujuannya untuk memengaruhi pendengar yang ada di Masjid. Retorika khotbah Jumat adalah cara seorang penutur menggunakan seni berbicaranya supaya apa yang disampaikan dapat mudah dipahami dan diikuti oleh jamaah muslim khususnya laki-laki pada saat mengikuti rangkaian salat Jumat (Safnil, 2003: 40).

Analisis pola retorika khotbah (sermon) yang disampaikan di gereja-gereja dalam bahasa Inggris sudah sering dilakukan. Cheong (1999) mengutip pendapat Moon dalam Safnil (2003: 39) menganalisis pola retorika sermon dan menemukan tiga bagian yang terdapat pada teks tersebut: Pendahuluan (introduction), batang tubuh (body), kesimpulan (conclusion). Menurut Moon, bagian pendahuluan dari sermon memiliki dua tujuan utama, yaitu untuk memastikan atau memperoleh perhatian pendengar dan menyampaikan topik pembicaraan dalam sermon tersebut. Bagian batang tubuh merupakan bagian utama dari sermon dan digunakan untuk menyampaikan proposisi yang didukung oleh kutipan, keterangan tambahan, ilustrasi, contoh dan aplikasi. Bagian terakhir atau bagian kesimpulan memiliki dua tujuan utama, yaitu untuk menyampaikan ringkasan sermonatau menekankan kembali pentingnya poin-poin yang telah disampaikan pada bagian batang tubuh dari sermon dan untuk mengajak atau memohon pendengar agar merespon atau merealisasikan secara individu semua poin yang telah disampaikan untuk mengabdi pada Tuhan.

Cara-cara yang digunakan oleh khatib dalam proses memengaruhi jamaah agar mereka meyakini ajaran atau nasihat yang disampaikan oleh khatib dengan harapan mereka akan menerapkan dalam kehidupan sehari-hari demi mencapai kebahagiaan di dunia dan di akhirat disebut retorika persuasi khotbah. Retorika persuasi dapat dijelaskan dengan menggunakan berbagai teknik-teknik persuasi. Khotbah Jumat di masjid NurIlahi Kelurahan Gunung Alam Kecamatan Arga Makmur Kabupaten Bengkulu Utara memiliki teknik persuasi berbeda-beda setiap khatib ketika membawakan khotbah, keempat khatib mempunyai teknik tersendiri dalam mempersuasi jamaahnya. Setiap khatib menggunakan bahasa-bahasa tertentu dengan teknik tertentu untuk memengaruhi pendengar, bahkan memberikan penguatan atau informasi kepada pendengar yang ada di masjid Nur-Ilahi Kelurahan Gunung Alam Kecamatan Arga Makmur Kabupaten Bengkulu Utara. Ada beberapa teknik persuasi yang digunakan untuk mempersuasikan jamaah yang diambil dari pendapat Johnstone (2008) dalam Sukarno (2013) yang dimuat dalam jurnal Retorika Persuasi Sebagai Upaya Memengarubi Jamaah Pada Teks Khotbah, teori Kridalaksana (1982), dan teori Wijana (2009). Berikut disajikan teknik-teknik persuasinya. 
1. Teknik persuasi secara langsung yaitu kalimat perintah yang sering diperhalus dengan ungkapan penghalus marilah atau mari.

2 Teknik persuasi secara tidak langsung tidak berupa kalimat perintah (modus imperatif), melainkan menggunakan kalimat yang bermoduskan non imperatif, yakni modus deklaratif atau interogatif.

3. Teknik persuasi dengan menggunakan majas merupakan bahasa kias yang dapat digunakan untuk menciptakan efek tertentu yang menimbulkan kesan imajinatif bagi pendengar atau pembacanya.

4. Teknik persuasi dengan menggunakan acuan atau referensi merupakan acuan yang berguna untuk mendukung pembahasan agar sesuatu yang disampaikan menjadi meyakinkan pendengar karena didukung oleh bukti atau sumber yang dipercaya.

5. Teknik persuasi dengan menggunakan cerita adalah kisah atau riwayat yang berisi kisah tentang nabi, sahabat nabi, Rasullulah, maupun cerita yang terjadi pada masa sekarang yang sesuai dengan topik bahasan pada saat berkhotbah.

6. Teknik persuasi dengan menggunakan analogi merupakan membandingkan antara dua benda atau dua hal yang berbeda sebagai usaha untuk memperluas makna kata guna memperoleh efek tertentu.

7. Teknik persuasi dengan menggunakan hubungan sebab-akibat adalah strategi persuasi yang sering digunakan dalam khotbah Jumat adalah penggunaan bentuk bahasa dengan hubungan silogisme sebab-akibat. Dalam hubungan silogisme ini ada dua kalimat atau lebih, yakni kalimat utama dan kalimat penjelas.

8. Teknik persuasi menggunakan harapan dan doa berisi harapan dan doa yang disampaikan oleh pembicara terhadap pendengar.

Teknik persuasi yang digunakan ditandai dengan ciri-ciri penanda lingual. Satuan lingual adalah penggalan dari perilaku kebahasaan yang bermakna atau paduan bentuk dan makna dari suatu sistem, tanpa atau dengan varian lahiriah yang berkontras dengan paduan lain dalam sistem itu atau segmen yang mendukung pola dalam berbagai tataran. Satuan lingual yaitu berupa fonem, dasar kata, afiks (termasuk morfem dasar dan morfem afiks), kata, frase, klausa, kalimat, paragraf, dan wacana. Satuan lingual yang menjadi objek kajian morfologi terdiri dari satuan lingual terkecil yang berupa bentuk dasar kata dan afiks atau morfem dasar dan morfem afiks, dan satuan lingual terbesar yang berupa kata (polimorfemis).

\section{METODE}

Penelitian ini menggunakan metode deskriptif dengan pendekatan kualitatif. Penelitian ini dilakukan di masjid Nur-Ilahi Kelurahan Gunung Alam Kecamatan Arga Makmur Kabupaten Bengkulu Utara Provinsi Bengkulu. Sumber data dalam penelitian ini adalah tuturan atau ujaran khatib yaitu Bapak Khaidir, Irfan Lubis, Heru, dan Jauhari pada saat khotbah yang direkam dan ditranskripsikan menjadi sebuah teks khotbah sebanyak 10 teks khotbah. Data dalam penelitian ini adalah tuturan atau ujaran yang mengandung teknik persuasi dalam retorika khotbah Jumat dan tuturan atau ujaran yang mengandung ciri penanda lingual dalam teknik persuasi pada retorika khotbah. Teknik yang digunakan 
untuk pengumpulan data teknik dokumentasi dan tehnik rekaman. Tehnik dokumentasi digunakan pada saat ingin melihat proses teks khotbah dibuat oleh khatib dan teknik rekaman digunakan pada saat ingin mengambil data khotbah Jumat yang dibacakan oleh 4 khatib.

Langkah-langkah analisis data dalam penelitian ini dilakukan dengan berbagai cara yaitu :

1. Transkripsi Ortografis Khotbah

Data penelitian diperoleh dari rekaman khotbah Jumat di masjid Nur-Ilahi Kelurahan Gunung Alam Kecamatan Arga Makmur Kabupaten Bengkulu Utara. Alat perekam yang dipakai menggunakan telepon genggam yang kemudian ditulis kembali hingga menjadi sebuah teks khotbah.

2. Mengidentifikasi Data

Teks khotbah tersebut kemudian diidentifikasi dengan cara menandai calon data yang mana yang akan menjadi data dalam penelitian. Data tersebut nantinya diidentifikasi kalimat mana yang termasuk ke dalam teknik persuasi dalam teks khotbah dan ciri penanda lingual yang ada pada teknik persuasi tersebut.

3. Mengklasifikasi Data

Data yang sudah diperoleh kemudian diklasifikasikan berdasarkan teknikteknik persuasi dan ciri penanda lingual pada teknik persuasi yang sudah ditemukan.

4. Menganalisis Data

Data yang telah diklasifikasi, kemudian dianalisis berdasarkan rincian masalah seperti jenis teknik persuasi yang digunakan ketika berbicara, kemudian mencari ciri penanda lingual dalam teknik persuasi yang telah ditemukan pada teks khotbah.

5. Merumuskan Kesimpulan

Data yang sudah dianalisis, kemudian disimpulkan terdapat berbagai teknik persuasi dan ciri penanda lingual dalam teknik persuasi tersebut sesuai dengan rincian masalah.

\section{HASIL DAN PEMBAHASAN}

Hasil penelitian ini yaitu ditemukan teknik persuasi dalam retorika khotbah Jumat dan ciri penanda lingual yang terdapat dalam teknik persuasi pada retorika khobah Jumat di masjid Nur-Ilahi Kelurahan Gunung Alam Kecamatan Arga Makmur Kabupaten Bengkulu Utara.

Bentuk teknik persuasi yang ditemukan pada bagian pendahuluan, isi, dan penutup khotbah Jumat adalah: (1) teknik persuasi secara langsung, (2) teknik persuasi secara tidak langsung, (3) Teknik persuasi dengan menggunakan acuan/referensi, (4) teknik persuasi dengan menggunakan analogi, dan (5) teknik persuasi menggunakan harapan dan doa.

Setiap teknik persuasi terdapat ciri penanda lingual dalam teknik persuasi tersebut antara lain: (1) Teknik persuasi secara langsung ditemukan enam variasi yang menjadi ciri penanda lingualnya yaitu menggunakan kata saya berpesan, marilah, kembali khatib mengingatkan, mari, kembali saya mengajak, dan selamatkan diri kita demi Allah selamatkan diri kita lari dari fitnah, (2) Teknik persuasi secara tidak langsung ditemukan ciri penanda 
lingualnya yaitu maksud/ makna dari kutipan khatib (dilihat berdasarkan maksud yang disampaikan dalam tuturan khatib), (3) Teknik persuasi dengan menggunakan acuan/referensi ditemukan ciri penanda lingualnya yaitu sebagaimana dalam Al-Quran, cerita badits Nabi Mubammad, Allab berfirman, menurut Abdullab bin Mubarok (ulama), Nabi Muhammad bersabda, Abu Dzar berkata, Rasulullab bersabda, kata para ulama, dialog Nabi dengan para sahabat, dan dijelaskan dalam hadits, (4) Teknik persuasi dengan menggunakan analogi ditemukan ciri penanda lingualnya yaitu analogi balans atau neraca yang dianalogikakan dengan amal perbuatan manusia, (5) Teknik persuasi menggunakan harapan dan doa ditemukan ciri penanda lingualnya yaitu mudah-mudahan dan semoga.

Setiap teknik persuasi yang ditemukan, ada satu teknik persuasi yang membedakan retorika khotbah dengan jenis-jenis retorika pada umumnya, yaitu teknik persuasi dengan menggunakan acuan/referensi (Al-Quran dan Hadis). Teknik ini menjadi ciri khas dari retorika khotbah yang tidak ada dalam retorika lain, karena teknik ini yang menjadi bukti agar yang disampaikan oleh khatib dapat dipercaya dengan acuan yang ada di dalam Al-Quran maupun Hadis.

A. Bentuk Teknik Persuasi

Dalam bagian ini, bagian-bagian yang dianalisis meliputi bagian pendahuluan, isi, dan penutup khotbah Jumat

1. Bentuk teknik persuasi secara langsung

Contohnya sebagai berikut:

(1) (II/1)

(D1/P1/K1/T1)

Mengawali khotbah Jumat pada kesempatan yang mulia ini, saya berpesan kepada para jamaah sekalian, khususnya kepada diri saya sendiri, marilah kita terus menerus meningkatkan iman dan takwa kitakepada Allah swt. (D1/P1/K1/T1)

Tuturan itu termasuk ke dalam teknik persuasi secara langsung, karena berupa ajakan yang digunakan khatib kepada jamaah untuk terus meningkatkan iman dan takwa kepada Allah swt yaitu ditandai dengan adanya ajakan kepada jamaah tersebut.

2. Bentuk teknik persuasi secara tidak langsung

Contohnya sebagai berikut:

(6)(II/5)

(D1/P2/K1/T4)

Seiring dengan itu mesti kita sadari bahwa umur kita telah bertambah satu tahun di 2020 ini, tetapi usia kita telah berkurang pula satu tahun, dan batas waktu serta kesempatan untuk berbuat dan beramal telah bertambah sempit dan berkurang juga. (D1/P2/K1/T4)

Dari tuturan tersebut secara tidak langsung khatib ingin mengajak jamah mumpung masih diberikan waktu oleh Allah untuk hidup di dunia, maka berbuatlah baik dan beramal saleh, karena umur kita terus bertambah tetapi usia terus berkurang.

3. Bentuk teknik persuasi dengan menggunakan acuan/referensi Contohnya sebagai berikut:

(16)(II/15) (D2/P2/K1/T1) 
Secara tegas Allah melarang menggunjing sebagaimana dalam Al- Quran, berikut:

Artinya:

"Hai orang-orang yang beriman, jaubilah kebanyakan dari prasangka, sesunggubnya sebagian prasangka itu adalah dosa dan janganlah kamu mencari-cari kesalahan orang lain dan janganlah sebagian kamu menggunjing sebagian yang lain.

Sukakah salah seorang di antara kamu memakan daging saudaranya yang sudah mati? Maka tentulah kamu merasa jijik kepadanya. Dan bertakwalah kepada Allah sesunggubnya Allah Maha Penerima tobat lagi maha Penyayang."

12)

(QS.Al-Hujarat:

Ada yang mengatakan bahwa sebab-sebab turunnya ayat tersebut berkenaan dengan dua orang sahabat Nabi saw. Yaitu, bahwa Nabi saw dalam sebuah perjalanan, beliau mengumpulkan seorang sababat yang fakir bersama dua orang sahabatyang kaya, agar orang yang fakir itu dapat ikut makan bersama dua orang sahabat yang kaya tersebut, dan supaya yang fakir itu datang lebih dabulu di tempat, mempersiapkan tempat tinggal dan makanan bagi keduanya.

Nabi saw, mengumpulkan Salman Al-Farisi dengan dua orang sababat yang kaya. Suatu hari sampailah di suatu tempat, namun Salman belum bisa mempersiapkan sesuatu makanan pun bagi kedua orang kaya itu.

Kedua orang itu berkata kepada Salman, "Pergilah kepada Rasulullah saw., mintalah kelebihan lauk pauk buat kita." Maka Salman pergi menghadap Rasulullah saw. Setelah Salman pergi, salah seorang dari keduanya berkata, "Jika ia sampai di sumur Samihah- sebuah sumur yang terkenal banyak airnya- tentu keringlah airnya."

Ketika Salman sampai kepada Rasulullah saw., ia menyampaikan apa yang diperintabkan oleh dua orang kaya tersebut kepada beliau. Nabi saw. bersabda kepada Salman, "Katakan, kepada keduanya, sunggub kamu berdua

telah makan lauk pauk." Salman kembali kepada kedua orang tersebut dan menyampaikan apa yang disabdakan Rasulullah saw itu kepada mereka berdua.

Lalu kedua orang itu datang menghadap kepada Nabi saw., seraya berkata, ya Rasulullah.”

"Kami tidak makan lauk-pauk apapun,

Rasulullah saw bersabda, "Sungguh aku melibat daging kemerah-merahan di dalam mulut kalian berdua, oleh karena kalian berdua menggunjing teman kalian." Kemudian turunlah ayat tersebut.

Ketika Nabi Mubammad saw. diisra'mi'rajkan, beliau diperlihatkan azab dan siksa bagi orang yang suka menggunjing. Nabi Mubammad saw bersabda. " Aku melewati sebuah kaum pada malam aku diisra'kan, mereka mencakar mukanya dengan kuku-kukunya sendiri. Lalu aku bertanya, 'Hai Jibril, siapakah mereka itu?' Jibril menjawab, "Mereka itu adalab orang-orang yang menggunjing manusia dan membicarakan harga diri merek.."

\section{(Al-}

Hadis)

Begitu pula adu domba, juga merupakan perbuatan yang sangat tercela dan berbahaya yang dilarang dalam islam. 
Allah swt telah berfirman:
Artinya:
"Yang banyak mencela, yang kian kemari menghambur fitnah. Yang
banyak menghalangi perbuatan baik, yang melampaui batas lagi banyak dosa, yang
kaku kasar, selain dari itu yang terkenal kejahatannya."

(QS. Al-Qalam: 11-

13)

"Yang kaku kasar, selain dari itu, yang terkenal kejahatannya."

(QS. Al-

Qalam:13)

Artinya:

Rasulullah saw. Bersabda, "Maukah kamu aku beritabukan mengenai orang

yang sejahat-jahat di antara kamu?" Yaitu, orang-orang yang berjalan (ke sana ke

mari)

dengan mengadu domba."

(HR.Ahmad)

Tuturan tersebut menjelaskan tentang larangan untuk berbuat menggunjing dan adu domba ke sesama manusia karena termasuk perbuatan tercela dan sangat berbahaya bagi pelakunya sendiri.

4. Bentuk teknik persuasi dengan menggunakan

analogi Contohnya sebagai berikut:

(9)(II/6) (D1/P2/K2/T4)

Sebagaimana kita maklumi bahwa akhir tahun atau awal tahun, kita

pergunakan untuk membikin balans atau neraca tahunan hidup dan

kehidupan serta terhadap amal perbuatan kita setahun yang silam, untuk mengetahui untung ruginya. (D1/P2/K2/T4)

Dari tuturan tersebut khatib menganalogikakan dua benda yaitu antara balans atau neraca dengan amal perbuatan kita yang bisa berat ke kiri dan berat ke kanan seperti sebuah neraca. Berat ke kiri disamakan dengan perbuatan buruk dan berat ke kanan bisa disamakan dengan perbuatan baik kita selama hidup, dari sana bisa mengetahui untung ruginya.

5. Bentuk teknik persuasi menggunakan harapan dan

doa Contohnya sebagai berikut:

(18)(II/30) (D3/P16/K1/T1)

Demikian khotbah yang saya sampaikan, mudah-mudahan Allah senantiasa memberikan taufik dan hidayah-Nya, sehingga kita mampu menjalankan hidup ini dengan amal saleh yang diridai-Nya dan menjauhi segala perbuatan tercela yang dimurkai-Nya, semisal menggunjing, mengumpat, mengadu domba dan perbuatan tercela lainnya. (D3/P16/K1/T1)

Tuturan tersebut adanya harapan agar Allah senantiasa memberikan hidayahNya kepada kita sehingga kita terus berbuat amal saleh dan menjauhi segala yang dilarang oleh Allah swt.

B. Ciri Penanda Lingual 
1. Teknik persuasi secara langsung ditemukan enam variasi yang menjadi ciri penanda lingualnya yaitu pada bagian pendahuluan menggunakan kata saya berpesan, marilah, kembali khatib mengingatkan, mari, kembali saya mengajak, dan bagian penutup menggunakan kata selamatkan diri kita demi Allah selamatkan diri kita lari darifitnah.

Salah satu contoh ciri penanda lingual kata marilah (20)(II/3) (D1/P1/K1/T2)

Marilah kita sejenak intinya untuk selalu bersyukur ke hadirat Allah swt atas segala limpahan rahmat yang diberikan kepada kita, sehingga pada hari ini kita masih dapat berkumpul di rumah Allah yang mulia ini dalam rangka melaksanakan salat Jumat secara berjamaah. (D1/P1/K1/T2)

Ciri penanda lingual yang menandai teknik tersebut persuasi secara langsung yaitu dengan adanya kata berupa ajakan seperti marilah

2. Teknik persuasi secara tidak langsung pada bagian pendahuluan, isi, penutup ditemukan ciri penanda lingualnya yaitu maksud/ makna dari kutipan khatib (dilihat berdasarkan maksud yang disampaikan dalam tuturan khatib).

Salah satu contoh ciri penanda lingual teknik persuasi secara tidak langsung (26)(II/5) (D1/P2/K1/T4)

Seiring dengan itu mesti kita sadari bahwa umur kita telah bertambah satu tahun di 2020 ini, tetapi usia kita telah berkurang pula satu tahun, dan batas waktu serta kesempatan untuk berbuat dan beramal telah bertambah sempit dan berkurang juga. (D1/P2/K1/T4)

Ciri penanda lingual yang menandakan bahwa tuturan tersebut teknik persuasi secara tidak langsung tidak adanya bukti tersurat, namun dalam penjelasannya maksud dari tuturan itu yaitu mengajak jamaah untuk terus berbuat dan beramal saleh, mumpung masih diberi waktu.

3. Teknik persuasi dengan menggunakan acuan/referensi ditemukan pada bagian isi khotbah yang ciri penanda lingualnya yaitu sebagaimana dalam Al-Quran, cerita hadits Nabi Mubammad, Allah berfirman, menurut Abdullab bin Mubarok (ulama), Nabi Muhammad bersabda, Abu Drar berkata, Rasulullah bersabda, kata para ulama, dialog Nabi dengan para sababat, dan dijelaskan dalam hadits.

Salah satu contoh ciri penanda lingual menggunakan kata Allah berfirman (34)(II/15) (D2/P10/K1/T1)

Begitu pula adu domba, juga merupakan perbuatan yang sangat tercela dan berbahaya yang dilarang dalam islam. (D2/P10/K1/T1)

\section{Allah swt telah berfirman:}

Artinya:

"Yang banyak. mencela, yang kian kemari menghambur fitnah. Yang banyak. menghalangi perbuatan baik, yang melampani batas lagi banyak dosa, yang kaku kasar, selain dari itu yang terkenal kejahatannya."

(QS. A1-Qalam: 11-13)

Ciri penanda lingual yang menandai tuturan tersebut persuasi menggunakan acuan yaitu berupa kata: Allah berfirman.

4. Teknik persuasi dengan menggunakan analogi ditemukan pada bagian pendahuluan dengan ciri penanda lingualnya yaitu analogi balans atau neraca yang 
dianalogikakan dengan amal perbuatan manusia.

Contohnya sebagai berikut:

(32)(II/6)

(D1/P2/K2/T4)

Sebagaimana kita maklumi bahwa akhir tahun atau awal tahun, kita pergunakan untuk membikin balans atau neraca tahunan hidup dan

kehidupan serta terhadap amal perbuatan kita setahun yang silam, untuk mengetahui untung ruginya. (D1/P2/K2/T4)

Ciri penanda lingual yang menandakan bahwa tuturan tersebut teknik persuasi menggunakan analogi ditandai dengan kata: balans atau neraca yang dianalogikan dengan amal perbuatan manusia.

5. Teknik persuasi menggunakan harapan dan doa ditemukan pada bagian pendahuluan, isi, dan penutup khotbah dengan ciri penanda lingualnya yaitu mudah- mudahan dan semoga.

Salah satu contoh ciri penanda lingual menggunakan kata mudah-mudahan

(30)(II/2) (D1/P1/K3/T1)

Dengan demikian mudah-mudahan kita termasuk ke dalam golongan hamba-Nya yang selamat dan bahagia baik yang di dunia maupun di akhirat. (D1/P1/K3/T1)

Ciri penanda lingual yang menandai tuturan tersebut persuasi harapan dan doa dengan adanya kata berupa: mudah-mudahan.

\section{PENUTUP}

\section{KESIMPULAN}

Berdasarkan hasil analisis penelitian dan pembahasan mengenai teknik persuasi dalam retorika khotbah dan ciri penanda lingual yang terdapat dalam teknik persuasi pada retorika khotbah yang sesuai dengan rumusan masalah, maka dapat disimpulkan sebagai berikut. (1) Pada bagian pendahuluan, isi, dan penutup khotbah 1 sampai khotbah 10 ditemukan lima teknik persuasi yaitu teknik persuasi secara langsung, teknik persuasi secara tidak langsung, teknik persuasi dengan menggunakan acuan/referensi, teknik persuasi dengan menggunakan analogi, dan teknik persuasi menggunakan harapan dan doa. (2) Ciri penanda lingual yang terdapat dalam teknik persuasi yaitu sebagai berikut.

(a) teknik persuasi secara langsung ditemukan enam variasi yang menjadi ciri penanda lingualnya yaitu menggunakan kata saya berpesan, marilah, kembali khatib mengingatkan, mari, kembali saya mengajak, dan selamatkan diri kita demi Allah selamatkan diri kita lari dari fitnah,

(b) teknik persuasi secara tidak langsung ditemukan ciri penanda lingualnya yaitu maksud/ makna dari kutipan khatib (dilihat berdasarkan maksud yang disampaikan dalam tuturan khatib), (c) teknik persuasi dengan menggunakan acuan/referensi ditemukan ciri penanda lingualnya yaitu sebagaimana dalam Al-Quran, cerita badits Nabi Mubammad, Allah berfirman, menurut Abdullah bin Mubarok (ulama), Nabi Mubammad bersabda, Abu Dzar berkata, Rasulullah bersabda, kata para ulama, dialog Nabi dengan para sababat, dan dijelaskan dalam hadits, (d) teknik persuasi dengan menggunakan analogi ditemukan ciri penanda lingualnya yaitu analogi balans atau neraca yang dianalogikakan 
dengan amal perbuatan manusia, (e) teknik persuasi menggunakan harapan dan doa ditemukan ciri penanda lingualnya yaitu mudah- mudahan dan semoga.

\section{SARAN}

Penulis menyadari bahwa dalam hasil penelitian ini belum sempurna, dalam penelitian ini belum semua teknik persuasi ditemukan. Hanya lima teknik persuasi yang ditemukan dalam penelitian sedangkan tiga teknik persuasi belum ditemukan pada penelitian ini yaitu teknik persuasi menggunakan majas, teknik persuasi menggunakan hubungan sebab- akibat, dan teknik persuasi menggunakan cerita. Maka penulis berharap teknik persuasi yang belum ditemukan bisa ditemukan di penelitian selanjutnya dengan objek penelitian tetap sama yaitu tetap meneliti retorika khotbah, hanya saja variasi jumlah khatibnya ditambah lagi, lokasi penelitiannya juga jangan hanya satu masjid tetapi variasi lokasi, dan juga teks khotbah yang diteliti lebih banyak lagi sehingga teknik persuasi yang belum ditemukan bisa ditemukan. Jika objek kajiannya berbeda, bisa menggunakan novel untuk mencari teknik yang belum ditemukan karena dengan menggunakan objek kajian novel di dalamnya banyak bahasa-bahasa yang mengandung majas, cerita, dan tentu ada hubungan sebab-akibat. Maka teknik persuasi yang belum ditemukan bisa ditemukan.

\section{DAFTAR PUSTAKA}

Anwar, G. 2003. Retorika Praktis: Teknik dan Seni Berpidato. Jakarta: PT Rineka Cipta. Hendrikus, D. W. 1991. Retorika. Yogyakarta: Kanisius.

Kridalaksana, H. 1982. Kamus Linguistik. Jakarta: PT Gramedia.

Oka, I. G. 1976. Retorik (Sebuah Tinjauan Pengantar). Bandung: Tarate.

Safnil. 2003. Pengantar Analisis Retorika Teks. Bengkulu: Perpustakaan UNIB Press. Sukarno. 2013. Retorika Persuasi sebagai Upaya Memengarubi Jamaah pada Teks Khotbah. Jurnal Humaniora, XXV (2), 216.

Wijana, Putu Dewa I. 2009. Analisis Wacana Pragmatik: Kajian Teori dan Analisis. Surakarta: Yuma Pustaka. 